\title{
LEI DA GRAVITAÇÃO UNIVERSAL E OS SATÉLITES: UMA ABORDAGEM HISTÓRICO-TEMÁTICA USANDO MULTIMÍDIA
}

\author{
The Law of Universal Gravitation and the satellites: \\ an historical-thematic approach using a multimedia
}

\author{
Elvis Vilela Rodrigues ${ }^{1}$. Erika Zimmermann ${ }^{2}$. \\ Ângela Maria Hartmann ${ }^{3}$
}

Resumo: Examina-se, neste artigo, o desenvolvimento de aulas de Física em que, usando-se uma multimídia, a Lei da Gravitação Universal é abordada de forma contextualizada a partir da História da Ciência e de um tema atual (os satélites). O objetivo foi examinar como estudantes de Ensino Médio aceitam e se envolvem nesse estudo. Usando uma abordagem metodológica qualitativa, a multimídia apresenta o que são e como funcionam os satélites artificiais, trazendo uma narrativa histórica desde as ideias de movimento do sistema planetário de Ptolomeu até as de Isaac Newton sobre o movimento dos corpos, culminando na Lei da Gravitação Universal. Entrevistas, observações de sala de aula e documentos produzidos pelos estudantes mostram que as imagens, os filmes e os textos contidos na multimídia enriquecem, de modo significativo, o conteúdo, facilitando o entendimento de conceitos da Física. A contextualização histórico-temática, por sua vez, produz maior envolvimento dos alunos no estudo da Física.

Palavras-chave: Ensino de Física. Ensino Médio. Tecnologia da educação. Multimídia.

\begin{abstract}
This article examines the development of physics classes in which, using a multimedia, the Law of Universal Gravitation is discussed in context from the History of Science and a current theme (the satellites). The objective was to examine how high school students accept and engage in this study using a qualitative methodological approach. Multimedia describes satellites, and brings a historical narrative from the ideas of Ptolemy's planetary motion to Isaac's ideas and his Universal Law of Gravitation. Interviews, classroom observations and documents produced by students show that the images, movies and texts contained in the significantly enriched multimedia content, facilitate the understanding of physics concepts. The historical and thematic context, in turn, produces greater involvement of students in physics.
\end{abstract}

Keywords: Physics teaching. High School. Educational technology. Multimedia.

\footnotetext{
${ }^{1}$ Secretaria de Estado de Educação (SEE/DF), Centro Educacional 04 de Taguatinga. QNG - Área especial 20.7213005. Brasília, DF, Brasil. elvisvilela@gmail.com

${ }^{2}$ Programa de Pós-Graduação em Educação, Universidade de Brasília. Brasília, DF, Brasil.

${ }^{3}$ Universidade Federal do Pampa, campus Caçapava do Sul. Caçapava do Sul, RS, Brasil.
} 
Rodrigues, E. V.; Zimmermann, E.; Hartimann, Â. M.

\section{Introdução}

Entre as inúmeras propostas de transformar a educação científica, estão as abordagens histórico-filosóficas e as temáticas e o uso dos computadores e de filmes de ficção científica como ferramenta de ensino-aprendizagem. Essas propostas têm por objetivo contextualizar o conteúdo estudado, tornando as aulas de Ciências mais interessantes e atraentes.

Contextualizar significa trazer à tona as relações e inter-relações circunstanciais que acompanham a construção do conhecimento científico (BRASIL, 2002). No entanto, contextualizar o conteúdo a ser ensinado não é tarefa fácil e os professores, até pouco tempo, não eram preparados para tal tarefa. Pesquisa de Zimmermann (1997) mostra que, até os anos 1990, na área de Ciências Naturais privilegiava-se um ensino meramente propedêutico ou técnico, com ênfase na memorização e aplicação de fórmulas. Esse ensino, descontextualizado, não levava em conta o desenvolvimento do conhecimento científico e sua transposição, desde a sua produção até chegar às salas de aula. Era um ensino que não se preocupava com as grandes transformações e recriações pelas quais passa o conhecimento e que acabava por descaracterizar o contexto inicial de descoberta e aplicação desse conhecimento no cotidiano.

Há bastante tempo Matthews (1995) vem insistindo na eficiência de abordagens contextuais no ensino de ciências, a partir das dimensões históricas, filosóficas e culturais do conteúdo científico a ser tratado em sala de aula. Defende o autor que essas dimensões sejam tratadas explicitamente, e não apenas incluindo alguns tópicos, biografias, datas e fatos da História da Ciência, denominadas de dimensões minimalistas (TEIXEIRA; FREIRE JR.; ELHANI, 2009). Também é interessante que se focalize a origem histórica do problema ou conteúdo a ser trabalhado e se mostrem as tentativas de solução que levaram à proposição de modelos teóricos, a fim de que o aluno tenha noção de que houve um caminho percorrido para se chegar a esse saber (BRASIL, 2006). É preciso, no entanto, ter o cuidado de não confundir contextualização com cotidiano. Embora a maioria dos fenômenos naturais, e dos avanços tecnológicos, faça parte do dia a dia de uma grande parcela da sociedade, sua explicação científica não ocorre com a mesma frequência. As pessoas explicam muitos fenômenos utilizando o chamado senso comum, mas essas explicações são limitadas a situações particulares (BRASIL, 2006). Enquanto o aluno chega à escola com conhecimentos empíricos originados da sua interação com a natureza e com outras pessoas, o conhecimento científico origina-se em problemas bem formulados. O professor deve, pois, problematizar a relação entre o que o aluno já conhece e o conhecimento que pretende ensinar. Não se trata, pois, de:

[...] partir do que o aluno já sabe e chegar ao conhecimento científico, pois esse não é apenas polimento do senso comum. O que deve ser visado é partir da reflexão crítica ao senso comum e proporcionar alternativas para que o aluno sinta necessidade de buscar e compreender esse novo conhecimento. (BRASIL, 2006, p. 51)

Uma abordagem contextualizada historicamente contribui para desenvolver, nos estudantes, uma visão crítica e questionadora (BRASIL, 2002). Os Parâmetros Curriculares Nacionais do Ensino Médio (PCN-EM) defendem que, ao estudar a "realidade" do ponto de 
Lei da gravitação universal e os satélites: ...

vista científico, o estudante estaria mais preparado para aprender os conceitos e teorias colocados pela Ciência em geral e pela Física em particular.

Uma das formas de contextualizar o ensino de ciências é inserindo a História, a Filosofia e a Sociologia da Ciência (HFS). Outra forma é partir de temas tecnológicos contemporâneos, realizando uma abordagem temática dos objetos de estudo.

\section{Abordagem histórico-filosófica no ensino de ciências}

Diversos autores defendem o uso da Filosofia e História da Ciência (HFS) no Ensino das Ciências, apresentando diversas vantagens para seu uso e empregando argumentos bastante parecidos (DUSCHL; HAMILTON; GRANDY, 1992; NERSESSIAN, 1995; MATTHEWS, 1995; PEDUZZI, 2001; MARTINS, 2006; SILVA, 2009). Segundo Martins (2006), a HFS não substitui o ensino comum, no entanto, o complementa de forma adequada, ajudando os alunos a terem maior clareza de como se chegou aos conceitos científicos. Para ele,

A História da Ciência nos apresenta uma visão a respeito da natureza da pesquisa e do desenvolvimento científico que não costumamos encontrar no estudo didático dos resultados científicos (conforme apresentados nos livros científicos de todos os níveis). Os livros científicos didáticos enfatizam os resultados aos quais a Ciência chegou - as teorias e conceitos que aceitamos, as técnicas de análise que utilizamos - mas não costumam apresentar alguns outros aspectos da Ciência. De que modo as teorias e os conceitos se desenvolvem? Como os cientistas trabalham? Quais as ideias que não aceitamos hoje em dia e que eram aceitas no passado? Quais as relações entre ciência, filosofia e religião? Qual a relação entre o desenvolvimento do pensamento científico e outros desenvolvimentos históricos que ocorreram na mesma época? (MARTINS, 2006, p. xvii)

Em relação a uma abordagem histórica e filosófica, Matthews (1995) afirma que a História, a Filosofia e a Sociologia da Ciência (HFS):

[...] podem humanizar as ciências e aproximá-la dos interesses pessoais, éticos, culturais e políticos da comunidade; podem tornar as aulas de ciências mais desafiadoras e reflexivas, permitindo, deste modo, o desenvolvimento do pensamento crítico; podem contribuir para um entendimento mais integral da matéria científica, isto é, contribuir para a superação do "mar de falta de significação" que se diz ter inundado nas salas de aula de Ciências, onde fórmulas e equações são recitadas sem que muitos cheguem a saber o que significam; podem melhorar a formação do professor auxiliando o desenvolvimento de uma epistemologia da Ciência e mais rica e mais autêntica [...]. (MATTHEWS, 1995, p. 165)

Para muitos autores (MATTHEWS, 1995; NEVES, 1998; PEDUZZI, 2001; DUARTE, 2006; TEIXEIRA; FREIRE JR.; EL-HANI, 2009), o uso de História, Filosofia e Sociologia (HFS) da Ciência é uma forma interessante de abordar conteúdos científicos no ensino 
Rodrigues, E. V.; Zimmermann, E.; Hartimann, Â. M.

de ciências. Os defensores da HFS advogam em favor de uma abordagem interdisciplinar e contextualizada historicamente, ou seja, uma educação em Ciências trabalhada em diversos contextos (ético, social, histórico, filosófico e tecnológico). Matthews (1995), em especial, chama a atenção para a necessidade de se apresentar, aos alunos, a Ciência como um conhecimento em construção, com interrogações que ainda estão por serem respondidas. Para o autor, $\mathrm{o}$ aluno pode e deve desenvolver o ato investigativo ao ser instigado a buscar respostas para essas interrogações.

\section{Abordagem temática no Ensino de Ciências}

Outros autores têm defendido um ensino de ciências a partir da abordagem temática (ACEVEDO DÍAZ, 1996; CRUZ; ZYLBERSTAJN, 2001; AULER et al., 2009), que possui uma perspectiva curricular cuja lógica de organização é a estruturação do que é estudado em temas (DELIZOICOV; ANGOTTI; PERNAMBUCO, 2002). Há autores que defendem que se incorporem, ao ensino de ciências, temas contemporâneos de ciência e tecnologia (CRUZ; ZYLBERSTAJN, 2001; AULER et al., 2009); e outros, que se abordem temas controversos (AULER et al., 2005; ZUIN; FREITAS, 2007). Esses autores acreditam que, de uma maneira ou outra, a abordagem temática pode acabar com a tendência tradicional de fragmentação no ensino de ciências, defendendo que a abordagem temática contribui para os alunos tornaremse mais críticos e reflexivos, compreendendo não só os conceitos científicos, mas a complexidade social. O estudo de temas, segundo Santos e Mortimer (2000, p. 13), "permite a introdução de problemas sociais a serem discutidos pelos alunos, propiciando o desenvolvimento da capacidade de tomada de decisão". A abordagem temática inverte o arranjo de apresentação do conteúdo, fazendo com que conceitos, modelos e teorias venham a reboque dos temas, ou seja, o tema acarreta a necessidade de se entenderem os conceitos (CARVALHO; GIL-PÉREZ, 2003).

\section{Abordagem histórico-temática no ensino de ciências}

Acreditando que uma abordagem histórico-temática da Ciência pode contribuir para tornar o estudo da Física mais interessante, agradável e, portanto, eficaz para a aprendizagem da Física por alunos de Ensino Médio (EM), elaborou-se uma multimídia, constituída por um conjunto de slides que abordam a Lei da Gravitação Universal (LGU) e o uso de satélites. Para a construção da multimídia, denominada de "Satélites", tomou-se como base o material produzido por Duarte (2006). A escolha do tema "satélites" visou inserir o aluno no contexto do desenvolvimento das teorias científicas que permitem, ao ser humano, explorar o espaço. Parte do conteúdo da multimídia foi estruturado para ser apresentado em doze aulas. Para a realização de atividades extraclasse, os alunos receberam cópias do material em compact disc (CD). Cabe ressaltar que, para a elaboração da multimídia, houve grande preocupação em se manter tanto o rigor científico quanto histórico do contexto e das ideias que culminaram na LGU.

Escolheu-se o tema dos satélites, pois, como defendem Cruz e Zylberstajn (2001, p. 172), "as Ciências são geralmente ensinadas com escassas referências a respeito das aplicações 
Lei da gravitação universal e os satélites: ...

à vida real e de sua relevância à vida pessoal dos alunos". Assim, a História da Ciência, tendo como tema "os satélites artificiais", é o conteúdo central da multimídia elaborada para o ensino da LGU. Por outro lado, sabe-se que os alunos apresentam problemas de aprendizagem dos conceitos relacionados a esse conteúdo da Física (ARTUSO, 2006). Esses problemas se devem, sobretudo, às dificuldades que têm para compreender as Leis de Newton, em particular a Terceira Lei (PIMENTEL, 2007; TALIM, 1999). Além disso, segundo Duarte (2006) o tema Gravitação se presta muito bem para ser contextualizado através de uma abordagem histórico-temática, que tenha por objeto de estudo os satélites.

A proposta foi, portanto, trabalhar o tema, em conexão com diferentes fatos históricos, tanto científicos como fatos históricos em geral, relacionando-os ao desenvolvimento das tecnologias e ao conhecimento científico necessário para colocar satélites em órbita. Na multimídia, são apresentados os conceitos, leis e teorias da Física desde Aristóteles até Newton, e a História contemporânea de como, por que e para que os satélites vieram a existir. Esse conteúdo é trabalhado por meio de: animações (Figura 1), vídeo documentários, poesias, fotografias, filmes (Figura 2), músicas, informações, reportagens etc. Com a multimídia, o aluno pode visualizar os conceitos e teorias através de animações como: (a) movimentos violentos na visão aristotélica; (b) modelo geocêntrico das esferas de cristal pensado por Aristóteles; (c) explicação de Hiparco para os movimentos violentos; (d) movimento retrógrado de um planeta observado da Terra por vários dias; (e) comparação das explicações do movimento retrógrado de Marte no modelo "ptolomaico" e "copernicano"; (f) fenômeno das marés; (g) colocação de satélites em órbita; entre outras. A multimídia apresenta também várias simulações, que visam promover a visualização: (i) do movimento retrógrado no sistema geocêntrico; (ii) do movimento retrógrado no sistema heliocêntrico; (iii) da Segunda Lei de Newton; e (iv) das Leis de Kepler.

Figura 1. Animações.

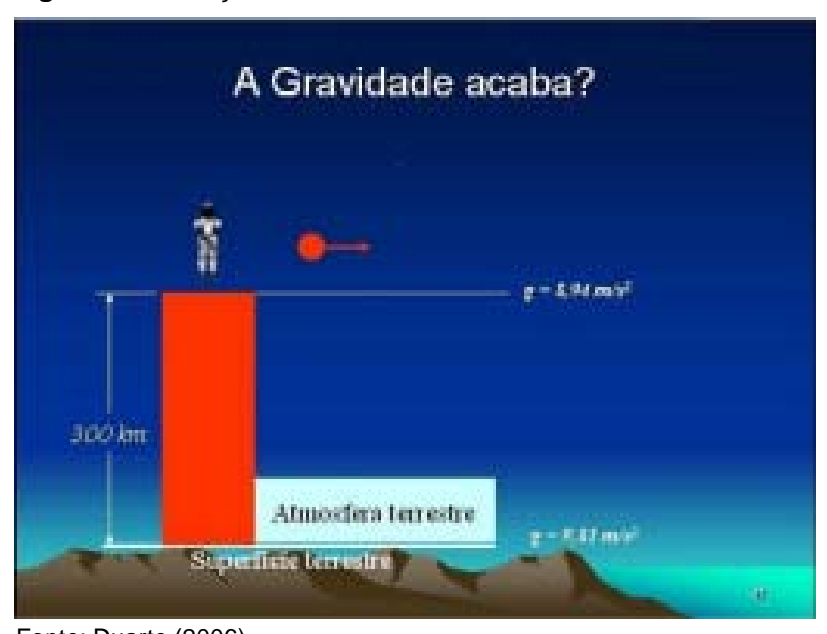

Fonte: Duarte (2006) 
Rodrigues, E. V.; Zimmermann, E.; Hartimann, Â. M.

Figura 2. Filme: crise dos mísseis em Cuba

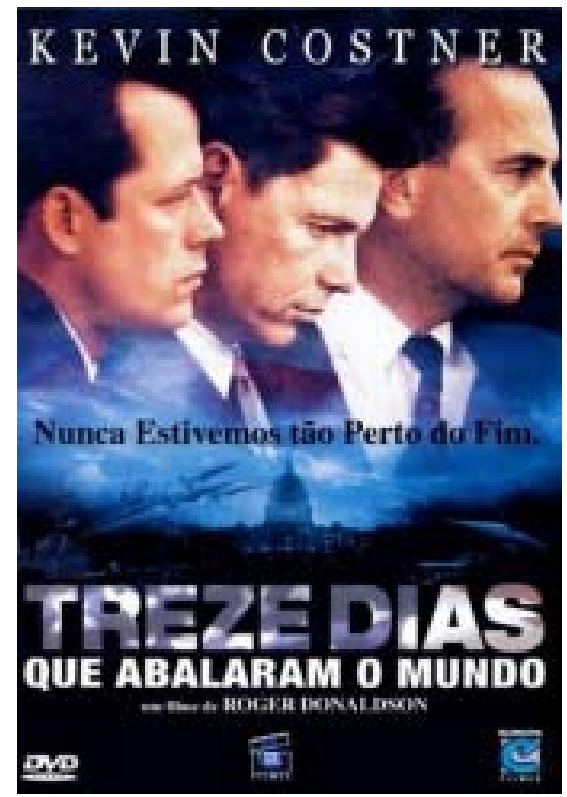

Fonte: Pessoa Filho (2005)

Para melhor compreensão de fenômenos físicos relacionados às Leis de Newton e ao posicionamento de satélites, foram inseridos, na multimídia, vídeos sobre: (1) as três leis de Newton; (2) o fenômeno das marés; (3) astronautas no espaço sujeitos a microgravidade (Figura 3); (4) satélite posicionado-se em órbita terrestre; (5) a crise dos mísseis; e (6) lançamento da Apolo 11. Esse material foi retirado da internet e/ou copiado de documentários e programas da TV fechada.

Figura 3. Vídeo documentário

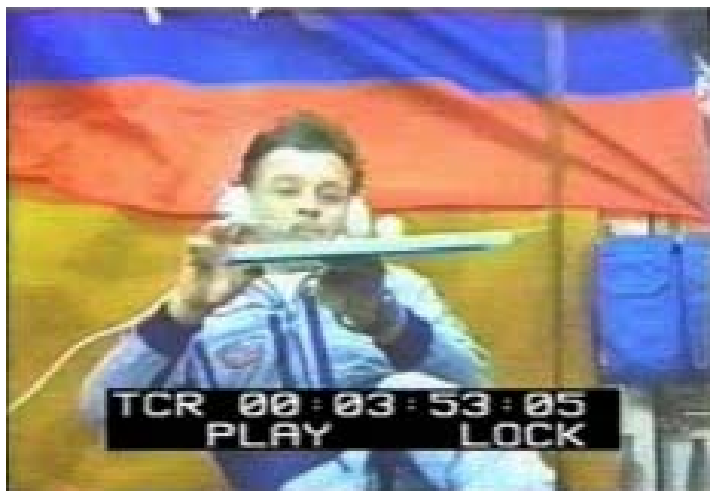

Fonte: Pessoa Filho (2005) 
Lei da gravitação universal e os satélites: ...

\section{Procedimentos metodológicos}

Para a realização da pesquisa, elaborou-se a multimídia, acima detalhada, com o objetivo de examinar se o conteúdo relacionado à LGU, quando apresentado de forma contextualizada, por meio da História, da História da Ciência, e com apresentação de sua utilização tecnológica (os satélites), favorece a aquisição de conceitos da Física. Um segundo objetivo da pesquisa foi descrever como alunos do primeiro ano do EM aceitam e se envolvem nesse estudo, ou seja, examinar se a contextualização apresentada pela multimídia beneficia a participação dos alunos e facilita a aquisição dos conceitos necessários para a aprendizagem da LGU. A multimídia serviu de suporte para o professor trabalhar esse conteúdo em sala de aula. Em suma, o objetivo geral dessa pesquisa foi examinar a contribuição da contextualização histórico-temática apresentada por uma ferramenta multimídia para a aprendizagem da LGU de alunos do primeiro ano do EM.

Optou-se por uma investigação de caráter qualitativo, tanto na forma como os dados foram coletados quanto na análise dos mesmos, tendo em vista que o ambiente da sala de aula foi o principal local de realização da pesquisa. Vale ressaltar que um dos autores desse trabalho desempenhou o papel de professor e de investigador. Desejava-se que o próprio professor reunisse os dados, para que eles pudessem ser ricos em detalhes e muito próximos do mundo de seus alunos-informantes (BOGDAN; BIKLEN, 1992). Os dados coletados, durante as aulas que foram todas videofilmadas, tiveram caráter fortemente descritivo (COHEN; MANION; MORRISON, 2000). Fizeram parte da coleta de dados, além da observação participante em sala de aula e as entrevistas, os trabalhos produzidos pelos alunos, tais como os textos por eles produzidos, questionários, exercícios etc. A observação se deu durante todo o tempo dedicado ao trabalho de campo, ou seja, durante as doze aulas previstas para o estudo do conteúdo. Todas as atividades de sala de aula foram documentadas e as aulas foram videofilmadas. O professor-pesquisador, como professor das duas turmas pesquisadas, teve o papel de membro aceito. Sempre que possível e necessário, foram tomadas notas descritivas de detalhes relevantes para a investigação e registrados episódios particulares. $\mathrm{O}$ mais cedo possível, após cada aula observada, as notas e os filmes foram revistos.

A pesquisa foi desenvolvida em uma escola da rede particular em que o ano letivo é dividido em três trimestres. A pesquisa em sala de aula aconteceu durante o último trimestre e, para realizá-la, foram escolhidas duas turmas (uma com 33 e outra com 34 alunos) de primeiro ano do EM. As salas onde ocorreram as aulas possuem lousa interativa - ferramenta tecnológica facilitadora da interatividade ao usar a multimídia. A lousa interativa (Figura 4), possibilita ao professor, durante a aula, acessar as ferramentas de editoração textual. A multimídia foi reproduzida em CD e distribuída aos alunos, que podiam explorar o seu conteúdo após as aulas ou mesmo antes.

Os dados coletados foram analisados a partir da sistematização das: (1) observações de sala de aula; (2) respostas dos alunos às entrevistas; e (3) das atividades realizadas pelos alunos em sala de aula e extraclasse (textos, respostas à questões prévias e as mesmas questões após discussão).

A análise de dados foi feita tomando-se por base os princípios da análise de conteúdo. Nesse tipo de análise ocorre a manipulação de mensagens (conteúdo e expressão desse conteúdo), para se evidenciarem os indicadores que permitam inferir sobre outra realidade que não a 
Rodrigues, E. V.; Zimmermann, E.; Hartimann, Â. M.

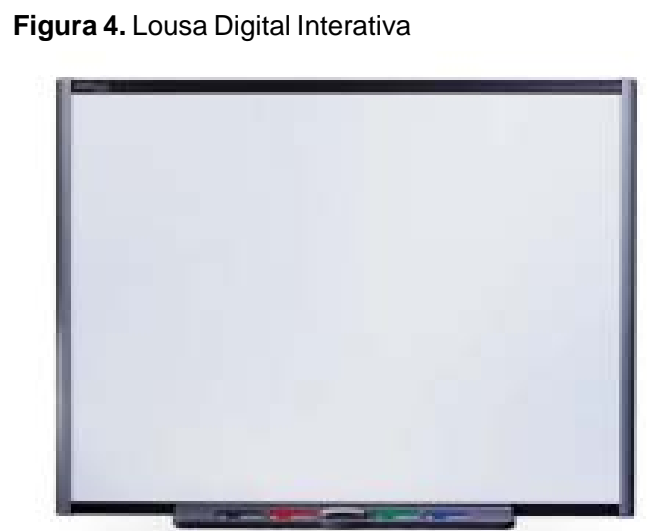

Fonte: Elaborado pelos autores

da mensagem (BARDIN, 1977). Durante a análise, buscou-se a presença de certas palavras e/ ou conceitos, no material empírico, para descrever o conteúdo das mensagens, tanto das entrevistas dos alunos quanto dos episódios e falas ocorridos em sala de aula e nas produções dos alunos. O processo de análise constituiu-se de três etapas: (1) pré-análise; (2) exploração do material e tratamento dos resultados; e (3) inferência e interpretação dos resultados.

Na pré-análise, os dados foram lidos para familiarização e codificação em vários níveis - palavras, sentenças, frases e temas, de forma a se estabelecerem as categorias. Essas categorias foram construídas como apanhados das principais ideias compartilhadas pelos alunos e demonstradas por episódios e falas durante as aulas e, mesmo, nos trabalhos de avaliação. Vale ressaltar que os dados que se mostraram mais produtivos para a análise foram os da observação de sala de aula e os das entrevistas. As categorias de análise nasceram dos dados e não foram, portanto, preestabelecidas. Elas foram examinadas conceitualmente e de forma relacional. Uma vez finalizada essa etapa, passou-se a explorar o material em maior profundidade, realizando-se triangulação das informações obtidas durante os procedimentos de pesquisa. Durante essa exploração, também foram elaborados diversos indicativos de interpretação. A última etapa da análise levou à inferência e interpretação dos resultados.

\section{O desenvolvimento da abordagem histórico-temática em sala de aula}

Durante a sequência de aulas em que se usou a abordagem histórico-temática, foram trabalhadas as competências e habilidades previstas no currículo da escola. Competências são tidas como qualificações humanas amplas e variadas, enquanto as habilidades são entendidas como qualificações mais específicas. Nesse sentido, uma competência em determinada área pressupõe um conjunto de habilidades. Elas incluem desde a aquisição de conhecimentos e procedimentos que permitam ao estudante comunicar-se e argumentar, até compreender e 
Lei da gravitação universal e os satélites: ...

enfrentar problemas, possibilitando-lhe condições de participar do convívio social de forma prática e solidária (BRASIL, 2002). Entre as competências e habilidades previstas nos Parâmetros Curriculares Nacionais para o Ensino Médio - PCNEM (BRASIL, 2002), na área de Física, encontram-se: (a) dominar a linguagem científica e traduzir as linguagens matemática, física e discursiva entre si; (b) compreender os fenômenos físicos e suas aplicações na produção tecnológica; (c) enfrentar situações-problema, valendo-se do conhecimento de fenômenos físicos para resolvê-los; e (4) construir argumentações, embasando-as no conhecimento de fenômenos físicos. As habilidades trabalhadas foram: (1) utilizar linguagem vetorial ao localizar posições, descrever deslocamentos e representar velocidades ou acelerações; (2) distinguir peso e massa, bem como suas unidades; (3) identificar as diferentes forças que atuam em objetos, em condições estáticas ou dinâmicas; (4) avaliar as acelerações em situações em que são conhecidas as velocidades de um objeto em sucessivos momentos; (5) identificar ação e reação, fazendo uso desse conhecimento em situações reais; (6) relacionar deslocamentos angulares, períodos, números de rotações em movimentos circulares; (7) analisar as condições de equilíbrio de um objeto em termos do cancelamento das forças e dos torques agindo sobre ele; e (8) relacionar força, aceleração gravitacional e os movimentos dos corpos celestes ou satélites artificiais.

Descrevemos a seguir, muito sucintamente por falta de espaço, o conteúdo e as atividades desenvolvidas durante as 12 aulas, de cinquenta minutos cada, em que o conteúdo da LGU foi tratado. É importante mencionar que as aulas sempre começavam com perguntas cujas respostas os alunos podiam reelaborar após a discussão feita com uso da multimídia. Assim, havia da parte do professor preocupação com o processo de ensino-aprendizagem, tendo sua fundamentação nas ideias de que os alunos podem reconstruir seus conhecimentos prévios.

$1^{a}$ aula: $O$ professor inicia a primeira aula apresentando um trecho do filme do diretor Stanley Kubrick 2001: uma odisséia no espaço, baseado no livro de Arthur C. Clarke. Ele orienta os alunos para que o revejam em casa e anotem as passagens que lhes chamarem atenção, levantando questões sobre a Física envolvida, pois o filme será retomado em aula. Os alunos são lembrados que, dessa aula em diante, tratariam do assunto satélites. Distribui-se, então, um questionário dividido em duas partes. Na primeira, os alunos deveriam responder de forma dissertativa à pergunta "O que é um satélite?". Na outra, de múltipla escolha, os alunos deveriam marcar com um "x" as opções que representavam, em suas concepções, exemplos de satélites. Após responderem, o professor, usando a multimídia, discutiu com eles a definição do termo satélite. Em seguida, pediu aos alunos que reescrevessem suas respostas, caso achassem necessário. Depois de os alunos terem reelaborado as respostas, o professor trabalhou com os alunos a parte da multimídia que define cada tipo de satélite. Como atividade extraclasse, solicitou aos alunos que pesquisassem quais são os satélites brasileiros em órbita e quais são suas funções. A aula terminou com uma grande discussão sobre os tipos e funções dos satélites, suas estruturas, suprimento de energia, sobre os usos militares desde os primeiros satélites lançados, começando pelo Sputnik. Essa discussão terminou com o professor anunciando: "Agora precisamos saber como se colocam essas 'máquinas' para girar em volta da Terra. Mas para isso, precisamos entender um pouco mais sobre a Física que governa o movimento dos satélites e, portanto, para isso vamos conhecer primeiro as ideias de Aristóteles sobre o universo". 
Rodrigues, E. V.; Zimmermann, E.; Hartimann, Â. M.

$2^{\text {a }}$ aula: $\mathrm{O}$ início da segunda aula foi conturbado, mas satisfatório. Ao invés de entrar diretamente no tema da aula, visão de mundo aristotélica, professor e alunos discutiram várias cenas do filme de Stanley Kubrick. Para não frustrar os alunos, que queriam continuar a discutir o filme, o professor apresentou uma lista de perguntas a respeito do filme, a serem respondidas em grupo e entregues como parte da avaliação. Ao terminar, os grupos receberam uma nova questão: "Você sabe como se coloca um satélite artificial em órbita?" Como a questão tinha relação com o filme, os alunos entraram em discussões calorosas. Após essa tarefa, usando a multimídia, o professor apresentou as ideias de Aristóteles sobre o Cosmo. Depois, os mesmos grupos de alunos responderem à pergunta: "Se os movimentos violentos exigem uma causa, o que faria uma pedra continuar se movimentando mesmo depois de perder contato com a mão do lançador?” Passou-se, então, a discutir a coerência das ideias de Aristóteles. Vale ressaltar que os alunos começaram a achá-las coerentes. Para terminar a aula, os alunos foram apresentados a trechos da peça Arcádia. Como atividade para casa, eles deveriam rever as ideias de Aristóteles e elaborar uma síntese, argumentando sobre as coerências e incoerências dessas ideias. Deveriam, também, responder à pergunta: "Você teria algum argumento convincente sobre o fato da Terra girar em torno do Sol? Quais argumentos você usaria para nos convencer de que a Terra gira ao redor do Sol?"

$3^{\mathbf{a}}$ aula: Após intensa discussão sobre que argumentos usariam para convencer alguém de que a Terra gira ao redor do Sol, a terceira aula versou sobre as ideias de Ptolomeu. Apoiando-se nas imagens apresentadas na multimídia, o professor iniciou essa discussão com a seguinte afirmação: "As idéias de Aristóteles eram bem aceitas. No entanto, o mundo aristotélico, no qual os planetas descreviam círculos em volta da Terra, não concordava com observações como as do movimento retrógrado". Assim, entrou-se na parte da multimídia que mostrava as ideias de Ptolomeu, e o professor solicitou aos alunos que, em grupos, respondessem à pergunta: "O que fez Ptolomeu para salvar a teoria geocêntrica?". Em seguida, professor e alunos discutiram, com a ajuda de animações contidas na multimídia, as duas grandes irregularidades planetárias, o movimento retrógrado e a variação do tempo requerido para percorrer o círculo. Essa discussão foi bastante produtiva e os alunos demonstraram muito interesse, parecendo ter entendido o movimento retrógrado após visualizá-lo nas animações. O professor aproveitou a oportunidade para apresentar, aos alunos, o filósofo Thomas Kuhn, mostrando que ele discute como Ptolomeu "salvou" a teoria geocêntrica introduzindo um complicado artifício - os epiciclos - para dar conta do movimento errante dos planetas. Ao final, o professor solicitou que os alunos, em casa, pesquisassem a teoria do Impetus e redigissem, com suas palavras, o que entenderam a respeito dela.

$4^{a}$ aula: A quarta aula teve como tema Copérnico. Já no início, o professor solicitou que, em grupos de quatro alunos, respondessem à pergunta: "Você tem ideia de como o sistema heliocêntrico de Copérnico explicava o movimento retrógrado dos planetas?" Após responderem, a história da vida de Copérnico e o sistema idealizado por ele foram discutidos em sala com auxílio da multimídia. O professor chamou atenção para o fato de que Copérnico só publicou o livro com suas ideias e hipóteses, quando estava às portas da morte. O professor aproveitou o momento para discutir as influências sociais, religiosas e políticas na produção científica.

$5^{a}$ aula: A vida e as ideias de Tycho Brahe constituíram a temática desta aula, que iniciou com a frase: "Foram Tycho Brahe, Kepler e Galileu, juntamente com as ideias de 
Lei da gravitação universal e os satélites: ...

Newton, que possibilitaram a ida do homem à Lua. Eles possibilitaram a presença desses satélites artificiais ao redor da Terra, que tanto temos discutido". A partir dessa introdução, as ideias de Tycho Brahe foram apresentadas e discutidas usando a multimídia. Ao final da aula, o professor solicitou que os alunos, de forma escrita e individual, defendessem o modelo planetário, entre os vistos até então, que eles achassem o mais próximo da realidade. Como atividade de casa, os alunos deveriam desenhar, em uma cartolina, o modelo planetário de Brahe.

$6^{\mathbf{a}}$ aula: A vida e as Leis de Kepler foram o tema desta aula. Durante a discussão, feita com auxílio da multimídia, Kepler foi apresentado como uma pessoa de inteligência penetrante e grande talento matemático, que, tendo trabalhado com Brahe, imaginou um universo constituído de seis esferas invisíveis para regular as órbitas dos planetas conhecidos. O professor destacou a harmonia do universo de Kepler, bem como suas três leis, usando diversas animações contidas na multimídia. Depois, o professor solicitou que os alunos respondessem, em grupos, as perguntas e fizessem alguns problemas do livro-texto, referentes às leis de Kepler. Pode-se perceber que os alunos realizaram a tarefa com entusiasmo, conversando calorosamente. Vale ressaltar a observação de que as conversas versavam sobre o trabalho de Kepler, não se tratando de conversas sobre temas adversos ao que estava sendo tratado em aula. Como atividade de casa, o professor solicitou que os alunos escrevessem um texto de, aproximadamente, vinte linhas, interpretando o poema de Olavo Bilac, Via Láctea, presente na multimídia.

$7^{a}$ aula: $\mathrm{Na}$ sétima aula foi trabalhado o poema de Olavo Bilac. Foi uma aula bastante descontraída. Uma aluna declamou Via Láctea para que os colegas, em seguida, realizassem um debate sobre as ideias contidas no poema. Notou-se que os alunos tiveram muita dificuldade na interpretação. Depois foram feitas discussões para reavivar as aulas anteriores, com intuito de que os alunos tivessem agora um quadro geral do desenvolvimento da Física do universo, desde Aristóteles até Kepler. Ao final da aula, o professor lembrou aos alunos que, na próxima aula, seria trabalhada a vida e a obra de Galileu Galilei, e, para tanto, pediu que eles fizessem uma pesquisa sobre o tema.

$8^{\mathbf{a}}$ aula: Nesta aula o professor trabalhou, portanto, a vida e obra de Galileu. Iniciou dizendo: "Continuaremos a galgar pela História da Ciência. Ela nos mostra que ao mesmo tempo em que Kepler trabalhava em Praga, mostrando que a Terra não é o centro do universo, na Itália outro homem também trabalhava no mesmo problema: Galileu Galilei”. Dito isso, discutiu tanto a vida particular de Galileu como seus problemas para defender o heliocentrismo. O professor procurou destacar a genialidade de Galileu mostrando como ele media o tempo (com a pulsação), até inventar um cronômetro de água, e que esse instrumento contribuiu para o desenvolvimento de suas ideias sobre a queda dos corpos. Os alunos puderam ver alguns de seus manuscritos reproduzidos na multimídia e assistiram a filmes de bombas sendo soltas de aviões, tanto sob o ponto de vista de quem está em uma aeronave como de quem está fora dela. De diversas maneiras foi ressaltada a genialidade de Galileu, que, além de outros feitos, adaptou o telescópio a partir de um "brinquedo", construído por um artesão holandês. Quase ao final da aula, os alunos assistiram partes do documentário do History Channel sobre Galileu. Depois, foram apresentados a trechos do livro Diálogos sobre os dois máximos sistemas do mundo. Eles puderam folhear o livro trazido à aula e ficaram muito curiosos e espantados, pois não acharam o livro nada parecido com o que imaginavam escrever "um cara que nem o Galileu". Por último, um aluno recitou o Poema para Galileu de Antônio Gedeão, tendo o professor 
Rodrigues, E. V.; Zimmermann, E.; Hartimann, Â. M.

feito as interpretações de alguns trechos. Como atividade para casa, lhes foi pedido que assistissem ao restante do documentário sobre Galileu e elaborassem uma síntese sobre as partes que acharam mais relevantes e interessantes, argumentando por que as acharam importantes.

$9^{a}$ aula: A nona aula foi utilizada para a confecção dos modelos planetários: geocêntrico e heliocêntrico. Essa atividade teve por objetivo facilitar a construção de modelos mentais sobre o tema trabalhado. A confecção dos modelos deveria enfatizar suas características marcantes e significativas. Para sua elaboração, a turma foi dividida em grupos de quatro alunos. Cada grupo recebeu papel branco e colorido, lápis de cor, tesoura e cola. Os alunos poderiam construir modelos estáticos ou dinâmicos. Ou seja, os elementos componentes de cada modelo poderiam ser fixados no papel ou poderiam estar soltos para que os alunos, através de seus movimentos, representassem os movimentos dos astros. Cada grupo montou e descreveu o seu modelo para, em seguida, apresentá-lo à turma. Como atividade de casa, o professor solicitou uma pesquisa individual sobre o fenômeno das marés.

$10^{a}$ aula: A décima aula teve como tema a obra e vida de Isaac Newton. A aula começou com o professor dizendo: "Lembrem-se que desde o início dessas aulas estamos querendo entender como os satélites são colocados em órbita. A cartada final para a formulação da teoria, que possibilitou o homem colocá-los em órbita, foi de Isaac Newton. É esse o cientista que vocês irão conhecer agora." Uma vez mais, essa aula foi repleta de filmes e animações. Os alunos gostaram muito de ouvir a história da maçã, mostrada em uma animação. O professor deixou claro tratar-se de uma lenda, "uma história inventada, mas que não está tão longe do que possa ter realmente acontecido a esse cara que acaba por unir o Céu e a Terra". À medida que era descrito o temperamento forte desse inglês, criado pela avó, sua crença em Deus e seus estudos de alquimia, percebeu-se muita curiosidade dos alunos, manifestada pelo grande número de perguntas. Nessa aula foi trabalhada apenas a biografia de Newton. Como atividade para casa foi solicitado, aos alunos, um texto narrativo sobre a parte da vida de Newton que mais havia lhes chamado atenção. Solicitou-se, também, que escrevessem as questões que eles ainda considerassem não esclarecidas. Cabe notar que os textos escritos pelos alunos, em sua grande maioria, mostram que eles conseguiram reconhecer Newton como um ser humano, "teimoso", "briguento", "crente em Deus", "cheio de defeitos" etc.

$11^{a}$ aula: A décima primeira aula teve como tema as Leis de Newton. As três leis para dinâmica e a lei da Gravitação Universal foram todas apresentadas com animações. A aula foi do tipo conceitual, os alunos não resolveram problemas numéricos, pois o objetivo era assimilar conceitos. Como atividade de casa, os alunos pesquisaram a aplicabilidade da Lei da Gravitação Universal de Newton nos dias atuais.

$12^{a}$ aula: A última aula foi utilizada para o estudo da Lei da Gravitação Universal de Newton. Nessa aula, com animações e com slides que traziam a reprodução dos desenhos originais de Newton, o professor chegou à dedução da Lei da Gravitação. Nessa aula, professor e alunos também discutiram os movimentos das marés, tendo por base a pesquisa dos alunos (vide nona aula). Foram se lembrando, com base no documentário, que Galileu se recusou a acreditar que a lua pudesse influenciar as marés. Depois, o professor discutiu com os alunos o conceito de microgravidade, lembrando, com a ajuda dos desenhos de Newton, que um satélite em órbita da Terra "está o tempo todo caindo em direção à Terra". Então os alunos, em grupos, calcularam o valor da gravidade a trezentos quilômetros de altura, numa menção fictícia de existir um prédio de apartamentos com essa altura. De posse do conceito de 
Lei da gravitação universal e os satélites: ...

microgravidade e desse cálculo, os alunos assistiram a diversos filmes de astronautas, em naves em órbita da Terra, fazendo brincadeiras sob a influência de microgravidade. Durante a aula e com a ajuda do professor, responderam diversas questões (APÊNDICE A).

\section{Resultados e discussão}

Os dados para esta pesquisa foram coletados a partir de entrevistas, observação de sala de aula (filmadas), e de todos os documentos produzidos pelos alunos. As filmagens tiveram por meta captar as falas ocorridas durante as interações professor-aluno e alunoaluno. Nas entrevistas, os alunos foram instigados a discutir e comentar: (1) como consideraram a contextualização histórica realizada durante as aulas de Física; (2) como perceberam as discussões de cunho filosófico durante essas mesmas aulas; (3) como perceberam o uso da multimídia; (4) o que mais os marcou com o uso do material; (5) o que gostariam que fosse modificado no material (e nas aulas); (6) o que chamou atenção na História da Ciência e na História Contemporânea; e (7) o que foi marcante sobre a tecnologia dos satélites.

\section{Interações de sala de aula}

O que mais chamou atenção durante as aulas foi a participação dos alunos. Por exemplo, na segunda aula os alunos chegaram excitados à sala de aula, eles tinham assistido 2001: Uma Odisséia no Espaço em casa e queriam, de toda maneira, discutir as passagens que haviam anotado. O plano era discutir o filme na terceira aula, mas se percebeu que essa era a hora, pois se o que se desejava era a motivação dos alunos para aprender, a discussão não poderia ser postergada. Assim, resolveu-se aproveitar a oportunidade e levar adiante a discussão. Como afirma Piassi (2007, p. 317), os filmes "exercem uma atração especial para os jovens". Foi isso que aconteceu com esses alunos, eles ficaram completamente fascinados e mostraram ter assistido ao filme com muita atenção, como apontam as interações verbais entre Nelson e Décio, abaixo transcritas.

Nelson: "Olhe... é que me chamou atenção... foi muito rápido, a cena foi rápida de mais, mas vocês não viram dentro da estação espacial orbital... os caras ficam de cabeça para baixo uns com os outros, não viram? Então quem viu?"

Décio: "Eu vi mas não entendi por que".

Nelson: "Bem,... eu acho...não sei se estou errado. Hei, será que estou errado, vou dizer, mas será que... espero não estar dizendo besteiras. Eu acho que... fiquei pensando e sabe me lembrei da máquina de lavar roupas que quando gira as roupas colam na lateral. É a mesma coisa lá em cima, não é professor?"

Décio: Não entendi, como assim?"

Nelson: "É a estação. Fica girando e os caras colam nas laterais como na máquina, ora." 
Rodrigues, E. V.; Zimmermann, E.; Hartimann, Â. M.

Cabe ressaltar que, durante essa discussão, se fez uso de muitas das perguntas apresentadas por Piassi (2007). Diversos alunos mencionaram esse episódio durante as entrevistas, destacando-o como um dos momentos mais produtivos para que pudessem entender os fenômenos físicos. Outros filmes fizeram sucesso na sala de aula, e provocaram muita interação entre professor e alunos e entre os alunos, como é o caso dos documentários sobre a Apollo 8 e sobre os efeitos da microgravidade. As observações mostraram que o que mais "deu samba foram os filmes", como disse um aluno durante a entrevista. Também fizeram sucesso diversos clips, dentre os quais um com os Beatles, que teve como objetivo mostrar que as pessoas viviam no meio da Guerra Fria, mas que também havia cultura, arte e boa música, como a desse grupo que, no final da década de 1960, veria o homem chegar à Lua.

Os alunos ficavam muito atentos e bastante excitados com os filmes. $\mathrm{O}$ mesmo não se pode afirmar sobre a leitura e interpretação das poesias, que foi a atividade que mais os entediou. Foi um clima que se observou na oitava aula, quando foi lido o Poema para Galileu de António Gedeão. Durante as leituras e o trabalho de interpretação das poesias, os alunos se dispersavam e acabavam tendo conversas paralelas. Isso ocorreu com quase todas as poesias apresentadas, sendo a de Olavo Bilac - Owvir Estrelas - a menos maçante para eles.

Muitas das fotografias que fizeram parte da multimídia provocaram interações produtivas, ou seja, conversas acaloradas com o professor e com os colegas, como o caso de uma reprodução de matéria veiculada no jornal "O Globo", intitulada "De Saddam aos laranjais".

Claudio: "Uauuu - espionagem por meio de satélites! Hehehe... e eu que não acreditava nisso. Professor... eu tinha um vizinho que ficava conversando comigo e... a gente ficamos (sic) olhando pro céu. Ele me ensinou a ver os satélites passando. Tinha que ter paciência... e de repente se via...er... era como uma estrela pequena que... andava lentamente. Nossa... era muito legal. Um dia ele me disse que eles espionavam... que viam tudo que faziamos aqui em baixo. Eu... claro.. eu não acreditei nele...mas agora... agora que ele já morreu...agora sei que não tava brincando... os caras podem mesmo ver tudo, heim? Caraca!".

As simulações e animações, em muitos casos, estimulavam os alunos a fazerem perguntas. Por exemplo, quando, em grupos, discutiam a animação sobre gravidade e se deram conta, após muitas conversas, que a órbita em que se encontra a Estação Espacial Internacional é de, aproximadamente, $353 \mathrm{~km}$ de distância da Terra, e que o valor da gravidade lá é de, aproximadamente, $8,9 \mathrm{~m} / \mathrm{s}^{2}$.

Laércio: "Cara, mas veja só a Estação Internacional, nós vimos na outra aula, ela está ...e ... mais ou menos isso que tem aí na animação". Marcos: "Ó véio... então a conta tá errada, num tá? Naquela altura... nós vimo (sic)...as coisas tava flutuando... num tava".

Laércio: "Hummm ...tava ... hum é mesmo, num tô entendendo ... a gravidade lá tem que ser zero. Num é? Professor ajuda aqui ...qual é o problema, tem alguma coisa errada".

Professor: "Alguém sabe? Alguém entendeu o que está acontecendo?" 
Lei da gravitação universal e os satélites: ...

Carmem: "Er ...será ... olha acho que é o que vimos que acontece com a Lua .... aquilo ... até parece meio esquisito ... mas professor ... isso não acontece .... é porque a Estação ... é como se ela estivesse sempre caindo para a Terra, não?”

Professor: "Isso ...isso Carmem, você esta correta ... mas como se diz isso? Quando você diz "caindo" (sinaliza aspas com os dedos) é como se a Estação estivesse lá em cima e nós aqui em baixo ...alguém sabe dizer o que a Carmem disse mas como se fosse um físico falando?”

A interação acima, não só mostra que a animação estimulou a conversa sobre a queda livre dos corpos como proporcionou que eles recordassem o que foi considerado em aulas anteriores. Convencionou-se, nesse trabalho, denominar de lembrança estimulada (uma das categorias de análise) quando slides, filmes ou vídeos provocavam a lembrança dos alunos.

Em suma, as observações mostraram que a contextualização do conteúdo, feita com o auxílio de filmes, documentários, animações, imagens e, até mesmo, músicas, provocava os alunos de modo a quererem saber mais, além do que apresentava a multimídia. A partir das observações, é possível concluir que aprender conceitos físicos com o uso das mais diversas "ilustrações contextualizantes" é tremendamente produtivo.

\section{Resultados das entrevistas}

As entrevistas foram realizadas com dois grupos de alunos. Aconteceram duas entrevistas com cada um dos grupos, que eram compostos por três alunos. Em sala de aula, alguns alunos se voluntariaram para serem entrevistados. Durante as entrevistas, tivemos um grupo com dois alunos da turma A e um da turma B; no outro, dois da B e um da A. De forma geral, as conversas dos alunos durante as entrevistas giravam ao redor de: decorar fórmulas; conteúdo do vestibular; história; história da Ciência; filosofia; tecnologia; e aulas descontraídas. A partir dessas palavras e de como foram relacionados pelos alunos durante as entrevistas, foram desenvolvidos os seguintes grupos: (1) abordagem histórico-temática; (2) uso de multimídia como material didático; (3) diversificação do material da multimídia; (4) interatividade e dinamicidade.

\section{(1) Abordagem histórico-temática}

Os alunos afirmaram gostar de Física quando o conteúdo é apresentado com base em uma abordagem histórica da Ciência, pois não gostam de ficar decorando e aplicando fórmulas. Dizem que isso deixa o conteúdo monótono.

Carlos: “[...] gosto da História, sim... o que não gosto é ficar só decorando fórmulas e resolvendo problemas e exercícios é monótono e ... muito chato. Com essa nova forma, sabemos como o conteúdo evoluiu ao longo do tempo. Eu acho isso muito interessante."

Lúcia: “[...] Me marcou muito poder estudar o progresso da Ciência ao longo do tempo, desde Aristóteles até Newton. É muito ...é dez ... é interessante ver que esses caras também tinham dificuldades ... hehehe ... talvez até como ... sei lá .. er .. igual a minha”. 
Rodrigues, E. V.; Zimmermann, E.; Hartimann, Â. M.

Mário: “[...] Nossa eu gostei muito, muito mesmo. É melhor, pois você não precisa só ficar ...só decorar fórmulas, você aprende as raízes da Física, você consegue estabelecer o próximo, consegue fazer passo a passo."

Pedro: “[...] Quando você explica a História de como surgiu aquilo tudo é ...é melhor, interessa muito mais e cria melhor forma de aprendizado".

No entanto, as entrevistas mostraram o medo dos alunos que esse material não os ajude a passar no vestibular.

Lúcia: “[...] pois é professor, tá tudo muito bem, tá tudo muito bom. As coisas que tem no CD são dez ...er ... mas ... mas e o vestibular? Eu aprendi muito, sei disso, me lembro, vamos dizer de cada aula ...mas ... er ... cá prá nós, isso aí cai no vestibular? Se não cai de nada adianta. Tudo bonitinho mas não dá para passar".

Visualizar a relação do conteúdo com o cotidiano é apontado por eles como interessante e importante, ou seja, a apresentação do conteúdo usando um tema como pano de fundo para contextualizar foi mencionada diversas vezes pelos alunos durante as entrevistas. As Orientações Curriculares para o Ensino Médio (OCEM) (BRASIL, 2006), na parte destinada aos conhecimentos da Física, chamam atenção para a importância da apresentação do cotidiano e da contextualização para uma melhor formação de nossos alunos.

José: “Gostei disso, gostei de estudar Física quando consigo visualizar o conteúdo em meu dia-a-dia, relacionando com tecnologia".

Décio: "Também gostei de estudar os satélites. É uma boa opção ...er ... muitas vezes a gente fica perguntado qual a necessidade da gente estudar isso e quando você pega o ponto da partida ... er ... isso vai te mostrar como os satélites chegaram ai em cima ... uma coisa que já existe você vê que é extremamente importante para nossa vida. É isso ...muito bom".

Os alunos acharam os textos que faziam parte do CD extremamente simples e fáceis de serem entendidos, excetuando-se as poesias. Ao comparar os textos que fazem parte da multimídia com os dos livros textos, todos foram unânimes e disseram que, para eles, os textos apresentados nos livros didáticos não os ajudam, pelo contrário, dificultam o entendimento dos conceitos.

Décio: “[...] O que dificulta na Física são os texto (sic) ...eles, que acabam te confundindo a gente na hora dos cálculos. Mas desta vez ...ixi ... os textos eram tranquilos". 
Lei da gravitação universal e os satélites: ...

Cabe ainda ressaltar que o tema satélites, segundo os alunos, "levanta o interesse pelo estudo da gravitação". Durante as entrevistas, os alunos afirmaram ter gostado de aprender Física partindo desse tema. Isso, segundo eles, fez com que pudessem entender o conteúdo, pois puderam "visualizar a aplicaşão no cotidiano" e entender "o desenvolvimento conceitual necessário para que aquela tecnologia fosse possivel".

Mário: "Acho bem melhor do que antigamente... quero dizer ... antigamente a gente ficava só jogava a fórmula e pronto. Dessa nova forma temos a noção de processo... er ... da História... e aonde você utiliza aquilo que está aprendendo".

Lúcia: "É uma boa opção... er...é que... muitas vezes a gente fica perguntando... qual a necessidade da gente estudar isso? E quando você pega do ponto de partida .. pega uma coisa que existe e você vê que é extremamente importante para nossa vida, fica mais fácil".

Carlos: "Vixi... veja... é que nessa era que estamos vivendo ... vivendo ... que é da tecnologia ... er ... você usar o tema satélites para explicar gravitação universal é ... é ótimo. Muito interessante, pois se você usa um tema atual ...er ... a gente tem TV, celular tudo tem a ver com satélite. Então você usa um tema como esse para explicar como as coisas que acontecem, intera muito mais ...é mais ... é mais emocionante... para ele [aluno] ver o que está acontecendo hoje e se ligar rapidamente".

\section{(2) O uso de multimídia como material didático}

Os alunos mencionaram gostar de explorar o material de forma autônoma, em casa, e de manipular os dados, assistir aos vídeos e filmes, e visualizar algumas das simulações e animações presentes na multimídia. Para Medeiros e Medeiros (2002), a simulação engaja os alunos em suas tarefas e, com seu alto nível de interatividade, favorece a aprendizagem.

Pedro: “[...] a simulação hum ...acho que isso é ... é um jeito mais interativo e deixa a aula mais dinamizada e é mais fácil pra gente estudar ... é ... é punk".

Já as animações favorecem a visualização, como foi defendido por eles, sem as quais há que se fazer muito esforço para se entenderem fenômenos como, por exemplo, o movimento retrógrado dos planetas. Sendo assim, pode-se dizer que a animação é um elemento de grande valia em aulas de Física, por ajudar os alunos a compreenderem inúmeros fenômenos de difícil visualização.

Os alunos apontaram os filmes e vídeos como forte atrativo. Afirmaram que eles eram muito bons e que, durante o estudo em casa, gostaram muito de assistir a alguns deles diversas vezes. 
Rodrigues, E. V.; Zimmermann, E.; Hartimann, Â. M.

Lúcia: “[...] uma coisa que gostei bastante foram os vídeo (sic), os filminhos ...o filme do Galileu olhando o candelabro na igreja ... medindo tempo com o dedo no seu pulso, nossa, muito legal ... os filmes é que dão muita dinâmica, dinamismo à aula".

Almeida (2007) é a favor do uso de filmes em sala de aulas de Física, pois os considera "[...] um objeto cultural de lazer que pode funcionar no ensino [...] das Ciências" (p. 1) que desperta "[...] emoções, trazendo informação e possibilitando a reflexão de quem o assiste" (ALMEIDA, 2007, p. 1).

\section{(3) Diversificação do material da multimídia}

Durante as entrevistas, os alunos, por diversas vezes, apontaram que "uma coisa boa no CD foi ter várias coisas diferentes", ou "ele não tinha sempre a mesma maneira de apresentar as coisas", isto é "ele era diversificado". Isso, para eles, foi de fundamental importância para "não cansar". A diversificação, junto com a interatividade propiciada pela multimídia, foi apontada pelos alunos como o mais interessante da ferramenta. Machado e Santos (2004), em estudo sobre a utilização de um aplicativo hipermídia (courseware), que também aborda a Gravitação Universal, ressaltam que a diversidade de recursos e informações permite uma exploração ativa, sob diversos enfoques e linguagens, contribuindo para a compreensão e a associação de ideias, e favorecendo o processo de ensino e aprendizagem. Trabalho de Bolacha e Amador (2003), que investiga a existência ou não de relação entre a organização da informação e o tipo aprendizagem e/ ou raciocínio decorrente, mostra que a estrutura hipertextual em rede favorece a flexibilidade cognitiva, promovendo aprendizagens combinatórias associadas a raciocínios interpretativos e explicativos, enquanto a estrutura hipertextual hierárquica favorece aprendizagens superordenadas e subordinadas. No caso da pesquisa aqui relatada, constata-se que a diversificação do material contribuiu para manter os alunos interessados em explorarem o conteúdo da multimídia.

\section{(4) Interatividade e dinamicidade}

Os alunos reafirmaram diversas vezes, durante as entrevistas, que apreciaram a interatividade proporcionada pela ferramenta multimídia, ou seja, a possibilidade de interação com a ferramenta, fazendo com que ela respondesse a essa ação. Para os alunos, se a aula não provocar "grandes interações", é sinal de que "não foi uma boa aula", como nas ocasiões em que eram apresentadas "aquelas poesias chatas". Eles acreditam que a possibilidade de intervir sobre a ferramenta e controlar o curso das atividades contribuiu para seu interesse pelo conteúdo estudado.

Lúcia: "É que com a utilização do $\mathrm{CD}, \ldots$ da tecnologia... dinamizou mais a aula e ficou até mais fácil prestar atenção e estudar".

Pedro: "Hum ...sim, também acho. Deve continuar dessa forma eu estou aprendendo e a interação é bem maior". 
Lei da gravitação universal e os satélites: ...

Para finalizar, cabe destacar que, contrariando nossas expectativas, os alunos também afirmam que seria interessante que as aulas fossem desenvolvidas não só como o uso da multimídia, mas também que gostariam de continuar tendo aulas "tradicionais". Por falta de tempo, não foi possível realizar um follow up para aprofundar essa questão. Esse é, portanto, um dos pontos que deverá ser aprofundado em pesquisas futuras.

\section{Considerações finais}

Este trabalho teve como objetivos descrever e examinar como alunos do $1^{\circ}$ ano do Ensino Médio aceitam e se envolvem no desenvolvimento do conteúdo da LGU, quando esse é trabalhado de forma contextualizada usando a História Contemporânea, História da Ciência, e a partir de um tema, nesse caso, os satélites, tudo tratado em uma multimídia, em CD, entregue aos alunos. Descreveu-se, rapidamente, como foi o desenvolvimento das aulas, usando a multimídia apresentada em uma lousa interativa, em duas turmas de EM de uma escola particular.

Após a análise dos dados empíricos, ficou evidente que a multimídia foi aceita pelos alunos com relativo sucesso, a despeito de iniciais resistências à mudança do estilo de aula a que estavam habituados. Cabe também ressaltar que a mudança de uma abordagem conteudista para uma contextualizada temática e historicamente foi criticada por alguns "por não ser matéria que cai no vestibular". Ao mesmo tempo, os alunos, por gostarem muito das novas tecnologias, afirmaram que usar o computador para estudar passou a ser muito mais interessante, e que o material, por ser interativo, instigou-os a pesquisar. A abordagem históricotemática dos conteúdos da Física é apontada pelos estudantes como um dos pontos altos da ferramenta. Segundo os alunos, a multimídia possibilitou uma maior dedicação à disciplina. Os alunos das duas turmas pesquisadas afirmaram se sentirem motivados a estudarem em casa, o que não era usual.

O tema de análise mais recorrente das observações de sala de aula foi a interatividade e o dinamismo. $\mathrm{O}$ material tornou as aulas bem mais dinâmicas e interessantes, aumentando a participação dos alunos. A análise do material empírico revelou que o ponto alto da multimídia foi a contextualização histórica. A História da Ciência, e a própria História Contemporânea, da forma que foram apresentadas, provocaram a curiosidade e a atenção dos alunos, modificando suas atitudes durante as aulas. A partir da análise das produções escritas entregues pelos alunos, também foi possível constatar mudanças em suas concepções prévias, tanto no que se refere à natureza da Ciência quanto aos conceitos físicos. Em relação à natureza da ciência, vários alunos, em relatos em sala de aula e no portfólio, mostraram espanto ao perceberem que os cientistas se equivocam e realizam grandes descobertas com a ajuda de ideias de outros. A concepção inicial dos alunos era a de que os cientistas construíam toda uma nova teoria sem o aporte de ninguém. Eles também não conheciam o caráter mutável das ideias científicas.

A mudança no entendimento de conceitos físicos também foi evidenciada, pois $81 \%$ dos alunos erraram a definição ou exemplos de satélites, na primeira aula, nas respostas dadas no questionário. Após a apresentação do material, a porcentagem de alunos que errou uma das duas perguntas foi reduzida a $24 \%$. É possível, assim, afirmar que a abordagem contextual temática influencia a aprendizagem do conteúdo. Ela facilita as 'conexões' intelectuais por unir ideias, teorias e conceitos através de filmes, imagens, animações, episódios etc. 
Rodrigues, E. V.; Zimmermann, E.; Hartimann, Â. M.

A pesquisa evidencia que o uso da contextualização, por meio de uma multimídia, amplia as possibilidades de se abordar o conteúdo de Física. Os alunos, durante as entrevistas, ponderaram que imagens, filmes e textos contidos em uma multimídia enriquecem significativamente o conteúdo da Física, dando "vida a essa matéria que é fria". Isso porque, com a multimídia, se é capaz de trazer tudo isso para a sala de aula e com detalhes que, tradicionalmente, são difíceis de descrever ou representar. Os resultados mostraram que os alunos consideraram as aulas interessantes e motivadoras, e que houve um amadurecimento acerca da relação da Física com as outras áreas do conhecimento, como disse um aluno: "a Física deixon de ser isolada, só existindo na sala de aula, ela foi para fora". Além disso, como eles tinham seu próprio $\mathrm{CD}$, podiam explorá-lo em momentos diferentes das aulas, o que os fez se engajarem com afinco nas atividades de aprendizagem promovidas em classe ou extraclasse. Pode-se concluir que o uso da multimídia, de abordagem histórico-temática, foi considerado, pelos alunos, como estimulante para estudar, e os ajudou a amadurecerem e se motivarem para aprender os conceitos.

Acreditamos que o material, por ser profundamente contextualizado, contribui para a aprendizagem dos alunos. Durante avaliação de aprendizagem, aplicada ao final do trimestre, os estudantes apresentaram bom rendimento, algo que não havia acontecido em anos anteriores, quando a ferramenta multimídia não foi utilizada. Além disso, arriscamo-nos a afirmar que o material, por apresentar relações entre a ciência, tecnologia e sociedade, pode contribuir para o letramento científico e a formação cidadã dos alunos (SANTOS, 2007). Vale ressaltar que há outras variáveis do processo de ensino, como a metodologia de trabalho usada na sala de aula, que também podem ter influenciado os resultados.

\section{Referências}

ACEVEDO DÍAZ, J. A. La tecnologia en las relaciones CTS: una aproximación al tema. Enseñanza de las Ciencias, Barcelona, v. 14, n. 1, p. 35-44, 1996.

ALMEIDA, M. J. P. M. Um olhar na perspectiva do ensino de inter-relações entre ciência, tecnologia e ambiente: o início do fim. Ciência \& Ensino, Campinas, v. 1, p. 1-5, nov. 2007. (número especial).

ARTUSO, A. R. O uso da hipermídia no ensino de física: possibilidades de uma aprendizagem significativa. 2006. 196f. Dissertação (Mestrado em Educação) - Universidade Federal do Paraná, Curitiba, 2006.

AULER, D. et al. Transporte particular x coletivo: intervenção curricular pautada por interações entre ciência - tecnologia - sociedade. Enseñanza de las Ciencias, Barcelona, p. 1-5, 2005. (número extra).

Abordagem temática: natureza dos temas em Freire e no enfoque CTS.

Alexandria: Revista de Educação em Ciência e Tecnologia, Florianópolis, v. 2, n. 1, p. 67-84, mar. 2009. Disponível em: <http://www.ppgect.ufsc.br/alexandriarevista/ numero_1_2009/Decio.pdf>. Acesso em: 8 nov. 2010. 
Lei da gravitação universal e os satélites: ...

BARDIN, L. Análise de conteúdo. Lisboa: Edições 70, 1977.

BOGDAN, R. C.; BIKLEN, S. K. Qualitative research for education: an introduction to theory and methods. Needham Heights: Allynand Bacon, 1992.

BOLACHA, E.; AMADOR, F. Organização do conhecimento, construção de hiperdocumentos e ensino de ciências da terra. Investigações em Ensino de Ciências, Porto Alegre, v. 8, n. 1, p. 31-52, 2003.

BRASIL. Ministério da Educação. Orientações curriculares para o ensino médio: ciências da natureza, matemática e suas tecnologias. Brasília: Ministério da Educação, Secretaria de Educação Básica, 2006.

Ministério da Educação. Parâmetros curriculares nacionais: ensino médio.

Brasília: Ministério da Educação, Secretaria de Educação Básica, 2002.

CARVALHO, A. M. P.; GIL-PÉREZ, D. Formação de professores de ciências. São Paulo: Cortez, 2003.

COHEN, L.; MANION; L.; MORRISON, K. Research methods in education. $5^{\text {th }}$ ed. London: Routledge Falmer, 2000.

CRUZ, S. M. S.; ZYLBERSZTAJN, A. O enfoque ciência: tecnologia e sociedade e a aprendizagem centrada em eventos. In: PIETROCOLA, M. (Ed.). Ensino de física: conteúdo, metodologia e epistemologia numa concepção integradora. Florianópolis: Editora da UFSC, 2001. p. 171-196.

DELIZOICOV, D.; ANGOTTI, J. A.; PERNAMBUCO, M. M. Ensino de ciências: fundamentos e métodos. São Paulo: Cortez, 2002.

DUARTE, R. C. B. Módulo de mecânica newtoniana com uso de abordagem

CTS-histórica. 2006. 231 f. Dissertação (Mestrado em Ensino de Ciências) - Instituto de Química, Universidade de Brasília, Brasília, 2006.

DUSCHL, R. A.; HAMILTON, R. J.; GRANDY, R. E. Psychology and epistemology: match or mismatch when applied to science education? International Journal of Science Education, London, v. 12, n. 3, p. 230-243, 1990.

MACHADO, D. I.; SANTOS, P. L. V. da C. Avaliação da hipermídia no processo de ensino e aprendizagem da física: o caso da gravitação. Ciência \& Educação, Bauru, v. 10, n. 1, p. 75-99, 2004.

MARTINS, R. A. Introdução: a história da ciência e seus usos na educação. In: SILVA, C.

C. Estudos de história e filosofia das ciências. São Paulo: Livraria da Física, 2006. p. xvii-xxx.

MATTHEWS, M. R. História, filosofia e ensino de ciências: a tendência atual de reaproximação. Caderno Catarinense de Ensino de Física, Florianópolis, v. 12, n. 3, p. 164-214, dez. 1995. 
Rodrigues, E. V.; Zimmermann, E.; Hartimann, Â. M.

MEDEIROS, A.; MEDEIROS, C. F. de. Possibilidades e limitações das simulações computacionais no ensino da física. Revista Brasileira de Ensino de Física, São Paulo, v. 24, n. 2, p. 77-86, 2002.

NERSESSIAN, N. Opening the black box: cognitive science and history of science. Osiris, Chicago, v. 10, p. 194-211, 1995.

NEVES, M. C. D. A história da ciência no ensino de física. Ciência \& Educação, Bauru, v. 5, n. 1, p. 73-81, 1998.

PEDUZZI, L. O. Q. Sobre a utilização didática da história da ciência. In: PIETROCOLA, M. (Org.). Ensino de física: conteúdo, metodologia e epistemologia numa concepção integradora. Florianópolis: UFSC, 2001. p. 236-250.

PESSOA FILHO, J. B. O contexto histórico da corrida espacial. Fortaleza, 2005. (Programa AEB Escola). 01 CD-ROM.

PIASSI, L. P. C. Contatos: a ficção científica no ensino de ciências em um contexto sociocultural. 2007. 453 f. Tese (Doutorado) - Faculdade de Educação, Universidade de São Paulo, São Paulo, 2007.

PIMENTEL, E. C. B. A física dos brinquedos: o brinquedo como recurso institucional no ensino da terceira lei de Newton. 2007. 187 f. Dissertação (Mestrado em Ensino de Ciências) - Instituto de Química, Universidade de Brasília, Brasília, 2007.

SANTOS, W. L. P. dos; MORTIMER, E. F. Uma análise de pressupostos teóricos da abordagem C-T-S (Ciência - Tecnologia - Sociedade) no contexto da educação brasileira. Ensaio: Pesquisa em Educação em Ciências, Belo Horizonte, v. 2, n. 2, p. 1-23, 2000.

SANTOS, W. L. P. dos. Educação científica na perspectiva de letramento como prática social: funções, princípios e desafios. Revista Brasileira de Educação, Campinas, v. 12, p. 474-492, 2007.

SILVA, C. C. Simposio: la historia de la ciencia en la enseñanza de las ciencias. Enseñanza de las Ciencias, Barcelona, p. 2480-2482, 2009. (número extra).

TALIM, S. L. Dificuldades de aprendizagem na terceira lei de Newton. Caderno Catarinense de Ensino de Física, Florianópolis, v. 16, n. 2, p. 141-153, ago. 1999.

TEIXEIRA, E. S.; FREIRE JR., O.; EL-HANI, C. N. A influência de uma abordagem contextual sobre as concepções acerca da natureza da ciência de estudantes de física.Ciência \& Educação, Bauru, v. 15, n. 3, p. 529-556, 2009.

ZIMMERMANN, E.The interplay of pedagogical and science related issues in physics teachers' classroom activities. 1997. 343 f. Thesis (Doctoral in Education) Department of Science and Technology Education, University of Reading, Reading, 1997.

ZUIN, V. G.; FREITAS, D. A utilização de temas controversos: estudo de caso na formação de licenciandos numa CTSA. Ciência \& Ensino, Campinas, v. 1, n. 2, jun. 2007. Disponível em: <http://www.ige.unicamp.br/ojs/index.php/cienciaeensino/article\%20/ viewFile/136/129>. Acesso em: 8 nov. 2010. 
Lei da gravitação universal e os satélites: ...

APÊNDICE A. Questões respondidas pelos alunos

1. Enuncie a lei da gravitação universal proposta por Isaac Newton;

2. As afirmativas seguintes costumam ser feitas por pessoas que não conhecem muito bem a Lei da Gravitação Universal. Apresente argumentos que mostrem que estas afirmativas não são corretas.

a) "A força de atração da Terra sobre um satélite artificial é nula, porque eles estão muito afastados de seu centro."

b) "Um foguete não será mais atraído pela Terra quando ele chegar a regiões fora da atmosfera terrestre."

3. Calcule a força de atração gravitacional entre o Sol e a Terra. Dados: massa do Sol $=2.10^{30} \mathrm{~kg}$, massa da Terra $=6 \cdot 10^{24} \mathrm{~kg}$, distância entre o centro do Sol e o centro da Terra $=1,5 \cdot 10^{11} \mathrm{~m} \mathrm{e} \mathrm{G}=6,7 \cdot 10^{-11} \mathrm{~N} \cdot \mathrm{m}^{2} / \mathrm{kg}^{2}$.

4. Dois navios de 300.000 toneladas cada estão separados por uma distância de 100 metros entre seus centros de massa. Calcule o valor da força de atração gravitacional entre eles. Dado: $\mathrm{G}=6,7.10^{-11} \mathrm{~N} \cdot \mathrm{m}^{2} / \mathrm{kg}^{2}$.

5. Determine a força de atração gravitacional da Terra sobre a Lua, sendo dados: massa da Lua $=1.10^{23} \mathrm{~kg}$; massa da Terra $=6 \cdot 10^{24} \mathrm{~kg}$; distância do centro da Terra ao centro da Lua $=4 \cdot 10^{5} \mathrm{~km} ; \mathrm{G}=6,7 \cdot 10^{-11} \mathrm{~N} \cdot \mathrm{m}^{2} / \mathrm{kg}^{2}$. 